\title{
Sequestro dos proventos do crime: limites à solidariedade na decretação de medidas assecuratórias
}

\author{
Seizing proceeds of crime: limits to solidarity \\ in decreeing preservative measures
}

\section{Guilherme Brenner Lucchesi ${ }^{\mathbf{1}}$}

Universidade Federal do Paraná - Curitiba/PR, Brasil

guilherme@lucchesi.adv.br

lattes.cnpq.br/1512135510310992

D orcid.org/0000-0001-9505-421X

Ivan Navarro Zonta ${ }^{2}$

Universidade Federal do Paraná - Curitiba/PR, Brasil

ivan@lucchesi.adv.br

lattes.cnpq.br/4385747084751669

http://orcid.org/0000-0002-2943-4086

Resumo: O cenário atual do combate à criminalidade organizada e institucionalizada acentua o fenômeno da patrimonialização do direito penal. Nesse contexto, é importante, tanto para a repressão de crimes quanto para o devido respeito a direitos fundamentais do imputado, que se observem o uso adequado e os limites das medidas assecuratórias previstas no Código de Processo Penal. Tais medidas referem-se às finalidades estabelecidas pelo Código Penal de tornar certa a obrigação

1 Doutor em Direito pela UFPR. Master of Laws pela Cornell Law School. Professor de Direito Processual Penal da Faculdade de Direito da UFPR. Sócio fundador do escritório Lucchesi Advocacia. Presidente do Instituto Brasileiro de Direito Penal Econômico - IBDPE, Gestão 2019/2021. Secretário-geral do Instituto dos Advogados do Paraná - IAP, Gestão 2019/2021.

2 Mestrando em Direito na UFPR. Especialista em Direito Penal e Processo Penal pela ABDConst. Graduado em Direito pela UFPR. Sócio do escritório Lucchesi Advocacia. 
de reparar o dano e de decretação de perdimento dos instrumentos, produtos e proventos do crime. Quando se trata de crimes cometidos em coautoria, deve haver limitação do quantum patrimonial que poderá ser alcançado pelas medidas assecuratórias quanto a cada imputado. Diferentemente da obrigação de reparar o dano, a qual possui natureza solidária por expressa previsão do Código Civil, o perdimento deve observar estritos limites subjetivos, em respeito à intranscendência da pena. Por conseguinte, o sequestro, medida assecuratória que visa constringir bens que, ao final, serão atingidos pelo perdimento, deverá respeitar o limite do enriquecimento ilícito efetivamente percebido por um agente delituoso específico, inexistindo solidariedade entre codenunciados nesse ponto.

Palavras-Chave: medidas assecuratórias; perdimento; enriquecimento ilícito; sequestro de bens.

ABSTRACT: The current state of organized and institutionalized crime control stresses the patrimonialization of criminal law. In this context, it is important, both for the repression of crimes and for the fundamental rights of the accused, that the proper use and limits of preservative measures provisioned by the Code of Criminal Procedure be observed. These measures refer to the purposes defined by the Penal Code to make certain the obligation to repair damages and to decree the forfeiture of instruments, products and proceeds of crime. In regard to crimes committed by multiple agents, the ammount of assets subject to preservative measures must be limited regarding each co-defendant. Unlike the obligation to repair damages, which has a solidary nature under the provisions of the Civil Code, forfeiture must observe strict subjective limits, with respect to the intranscendence of criminal penalties. For example, seizure of assets, a preservative measure that aims to constrain goods that, in the end, will be affected by forfeiture, is restricted by the unjust enrichment effectively perceived by a criminal agent, with no solidarity among these co-defendants at that point.

KEYWORDs: preservative measures; forfeiture; unjust enrichment; seizure of assets.

SUMÁRIO: Introdução; 1. Medidas Assecuratórias Previstas na Legislação Processual Penal; 1.1. As medidas assecuratórias do Código de Processo Penal; 1.2. Previsões em legislação extravagante; 2. Referibilidade Material das Medidas Assecuratórias; 2.1. A obrigação de reparação do dano; 2.2. Perdimento do produto e proventos do crime; 3. Os Limites Subjetivos do Perdimento de Bens; 3.1. A 
solidariedade da obrigação de reparar o dano; 3.2. Inaplicabilidade da solidariedade ao perdimento do enriquecimento ilícito; 4. Solidariedade nas Medidas Assecuratórias; 4.1. Solidariedade no arresto e especialização de hipoteca legal; 4.2. Solidariedade no sequestro; Conclusão; Referências.

\section{INTRODUÇÃO}

Embora frequentemente empregado em contexto desrelacionado ao estudo técnico-científico do direito penal e processual penal, o universalmente conhecido brocardo "o crime não compensa" acaba por ilustrar, acidentalmente, um dos atuais aspectos problemáticos que reclamam a atenção redobrada dos estudiosos do direito criminal: o crescente alcance patrimonial das políticas e instrumentos de combate ao crime.

Analisar se algo compensa ou não demanda, em resumo, comparar seus custos e proventos. Se os custos forem maiores que os benefícios a serem auferidos, a atividade ou finalidade perseguida não compensará. É com base nessa lógica que se pode afirmar que o dito popular está mais atual do que nunca, pois é fácil perceber que, tanto no Brasil quanto nos países cujas tradições jurídicas e/ou teorias frequentemente (nem sempre acertadamente) influenciam o direito penal pátrio (v.g. Estados Unidos da América), a tendência comum é patrimonializar a repressão criminal. Visa-se atingir o patrimônio do agente criminoso como um fim em si mesmo ${ }^{3}$, não mais como um mero adicional às penas privativas de

3 “Nesse contexto, é somente através da perda dos bens que foram utilizados como instrumentos, produtos ou ainda proveitos do crime, bem como daqueles bens ou valores que são presumíveis terem sido adquiridos por condutas criminosas e do efetivo auxílio mútuo entre países, a possibilidade de mitigar o real poder e reter as atividades das organizações criminosas que, atualmente, são os principais inimigos da sociedade livre.” (LINHARES, Sólon Cicero. Confisco de bens: Uma medida penal, com efeitos civis contra a corrupção. São Paulo: RT, 2016. p. 96). No mesmo sentido, v. CORRÊA JUNIOR, Alceu. Confisco penal: alternativa à prisão e aplicação aos delitos econômicos. São Paulo: IBCCRIM, 2006. p. 165-166. Ainda, v. RIOS, Rodrigo Sánchez; PUJOL, Luiz Gustavo. Confisco alargado: reflexões acerca de suas possibilidades no 
liberdade, e sim de forma a ensejar tamanha perda patrimonial que se desencoraje tão somente por isso a prática delituosa.

Principalmente a partir da operação "Lava Jato", no cenário nacional, a busca pela utilização de instrumentos processuais e a fixação de sanções (em sentido lato) que possuam efeitos de natureza pecuniária/ patrimonial têm se tornado não somente carros-chefes da atuação ministerial, mas símbolos de vitória e represália ${ }^{4}$ contra a criminalidade no imaginário popular. Não é por outro motivo que inúmeras manchetes e notícias alardeiam insistentemente o "bloqueio de milhões em paraísos fiscais”, a apreensão de veículos e obras de arte de valor estratosférico”, "a recuperação de bilhões aos cofres públicos" etc. ${ }^{5}$

Esse fenômeno tem relação direta com o foco crescente dado à face moderna da criminalidade sistêmica, marcada por organizações criminosas integradas por inúmeros agentes e instituições privadas e públicas, e cujas repercussões e danos alcançam cifras por vezes bilionárias.

Nesse contexto, tanto a atividade legislativa quanto a judiciária passam a empregar esforços intensos a fim de atingir de forma severa os bolsos dos agentes criminosos que porventura acabem sob a mira da persecução criminal. O primeiro aspecto dessa nova forma de se aplicar o direito penal consiste na mutação gradual do modo em que o Ministério Público e o juízo criminal aplicam dispositivos já existentes na lei penal e processual penal, que permitem alcançar o patrimônio do agente delituoso ${ }^{6}$. Como exemplo, as próprias medidas assecuratórias previstas há

ordenamento jurídico brasileiro. Revista Brasileira de Ciências Criminais, v. 118, p. 123-158, jan.-fev. 2016. p. 124-126.

4 O emprego do termo é deliberado, pois evidencia a ocasional ausência de neutralidade na aplicação de medidas assecuratórias por parte de membros do Ministério Público e do Judiciário. Nesse ponto, une-se ao estudo técnicocientífico do trabalho uma pontual crítica quanto à forma em que as medidas assecuratórias são por vezes manejadas.

5 "Subvertendo as razões do discurso tradicional, tem-se alçado o Direito Penal - e mesmo o direito processual penal, por meio de um recorte constante nas garantias constitucionais - em prima ratio, ou por vezes, sola ratio de uma pretensa política criminal voltada à prevenção de condutas criminosas complexas.” (RIOS, R. S.; PUJOL, L. G. Op. cit., p. 154).

6 V. LOPES, João Felipe Menezes. Confisco de bens como instrumento de combate à criminalidade organizada: análise dos regimes estrangeiros e de sua 
décadas no CPP, mas que até poucos anos sequer eram objeto de atenção em comparação às penas corporais.

O segundo aspecto corresponde à criação de novos dispositivos de lei especialmente destinados à apreensão e confisco de bens e valores na seara criminal. O mais recente e relevante exemplo, provavelmente, consiste no confisco alargado estabelecido no art. 91-A do $\mathrm{CP}^{7}$, como resultado da Lei n. ${ }^{\circ} 13.964$, de 2019 , decorrente do redundantemente batizado "Projeto de Lei Anticrime".

Todos esses fatores confluem para um cenário desafiador, em que o profissional e o estudioso do direito penal enfrentam cada vez maior dificuldade para delimitar com exatidão os limites da responsabilização pecuniária decorrente de um fato delituoso, ante a incidência por vezes simultânea das penas de multa, condenação à reparação de danos, perdimento dos proventos do crime, incidência de multa civil e/ou administrativa etc. Embora a sentença condenatória, via de regra (isso nem sempre é observado na prática), defina estritamente todas as penas e efeitos da condenação (ao menos na seara criminal) ${ }^{8}$, antes desse marco processual ainda não se pode delimitar com segurança - mesmo quando aplicadas medidas assecuratórias tais quais o sequestro - quais serão os efeitos patrimoniais incidentes sobre cada investigado ou acusado.

E mais: em se tratando de delitos perpetrados por diversos agentes, com efeitos danosos e/ou de enriquecimento que ultrapassa a esfera individual do patrimônio de cada um dos autores, esbarra-se na dificultosa tarefa de delimitar se, quando e quanto do patrimônio de cada agente deve responder pelo dano e enriquecimento decorrentes da atividade conjunta.

Isso dá margem, muitas vezes, a violações às garantias ne bis in idem e de intranscendência das sanções penais, que se abatem sobre direito

compatibilidade com o ordenamento jurídico brasileiro. Revista da AJUFE, São Paulo, v. 95, p. 207-240, 2015.

7 Formas semelhantes de confisco, baseadas na suposta diferença entre o patrimônio real e o patrimônio lícito do acusado - ou seja, havendo evidências de enriquecimento ilícito -, especialmente no contexto de organizações criminosas, já figuram na legislação de outros países, como Espanha, Colômbia e Itália. Cf. LOPES, J.F.M. Op. cit., p. 210-216.

8 NICOLLIT, André. Manual de processo penal. 7. ed. Belo Horizonte: D’Plácido, 2018. p. 941-943. 
que, assim como a liberdade de locomoção, é fundamental e assegurado com destaque pela Constituição: a propriedade.

Some-se a isso a utilização atécnica das medidas assecuratórias típicas previstas pelo CPP, ou mesmo a utilização de medidas amorfas ou genéricas, que sequer visam se conformar a uma das formas específicas trazidas pela lei processual penal ${ }^{9}$, e tem-se por resultado um panorama que demanda sério restabelecimento da aplicabilidade estrita e dos limites de cada uma dessas medidas patrimoniais.

Para ilustrar a repercussão prática dos problemas mencionados, considerem-se os seguintes casos:

\section{Caso 1:}

A e B, empresários, praticam o crime de corrupção ativa, entregando a $\mathrm{C}$, funcionário público e autor crime de corrupção passiva, vantagem indevida na monta de $\mathrm{R} \$ 100.000,00$ (cem mil reais), provenientes do patrimônio lícito de A; em contrapartida, C lhes favorece com a prática de ato administrativo em desacordo com a lei, o qual não proporciona a $\mathrm{A}, \mathrm{B}$ ou suas empresas vantagem econômica direta. O Ministério Público oferece denúncia contra os três e requer ao Juízo criminal a decretação de bloqueio de valores, sobre o patrimônio - lícito ou ilícito - de cada réu, no valor de $\mathrm{R} \$ 100.000,00$ (cem mil reais). Deferido o bloqueio, são constritos os valores de $\mathrm{R} \$ 100.000,00$ na conta de $A, R \$ 15.000,00$ na conta de B (insuficiência de saldos), e R $\$ 1.000,00$ na conta de C (insuficiência de saldos).

\section{Caso 2:}

$\mathrm{X}$ e Y praticam estelionato contra Z, causando prejuízo na monta de $\mathrm{R} \$ 100.000,00$ (cem mil reais) em dinheiro vivo. Na divisão do valor obtido, $X$ fica com $\mathrm{R} \$ 70.000,00$, com o que adquire um veículo, e Y com $\mathrm{R} \$ 30.000,00$, escondidos dentro de uma maleta, em sua casa. Oferecida a denúncia, o Ministério Público requer e o juízo decreta o sequestro de bens e valores na monta de

9 ESSADO, Tiago. A perda de bens e o novo paradigma para o processo penal brasileiro. Dissertação - Mestrado em Direito - Programa de Pós-graduação em Direito da Universidade de São Paulo, São Paulo - SP, 2014, p. 38. 
$\mathrm{R} \$ 100.000,00$, quanto a cada réu, o que acarreta, quanto a $\mathrm{X}$, a apreensão do veículo e o bloqueio de $\mathrm{R} \$ 50.000,00$ (origem lícita) em sua conta, e, quanto a Y, o bloqueio de $\mathrm{R} \$ 60.000,00$ de origem não especificada em sua conta. O dinheiro em espécie mantido por Y não foi objeto de busca.

Os casos concretos formulados acima buscam sintetizar a problemática que se apresenta cotidianamente nos tribunais, e buscam problematizar a correta aplicação das medidas assecuratórias, principalmente quanto às suas finalidades e limites subjetivos. Após o desenvolvimento dos fundamentos deste estudo, buscaremos retomar os casos e propor suas respectivas resoluções.

Para tanto, na Seção 1 abordaremos breve revisão das medidas assecuratórias previstas na legislação pátria. Na Seção 2, trataremos da referibilidade dessas medidas às finalidades de perdimento de produtos e proventos do crime e condenação à reparação de danos. Na Seção 3, analisaremos os limites subjetivos aplicáveis a essas consequências patrimoniais da condenação criminal. Ao final, exporemos nossas conclusões quanto aos limites subjetivos aplicáveis à medida de sequestro, buscando, sem pretensão de esgotamento, apontar a relevância e a necessidade do estudo acurado sobre o alcance patrimonial em matéria criminal, focando especificamente no sequestro de bens e em alguns limites que esse instrumento deverá observar, a fim de que seja aplicado como legítima ferramenta de combate ao crime, mas sem ofensas ilegais ao direito fundamental de propriedade.

\section{Medidas Assecuratórias Previstas na Legislação Processual Penal}

O ponto inicial do breve estudo, naturalmente, será a descrição sumária das formas típicas de medidas assecuratórias ${ }^{10}$ que o legislador

10 Ao logo de toda a pesquisa, tomou-se por base fundamental, em apoio à legislação, a obra SAAD GIMENES, Marta Cristina Cury. As medidas assecuratórias do Código de Processo Penal como forma de tutela cautelar destinada à reparação do dano causado pelo delito. Tese (Doutorado em Direito) - Programa de Pós-graduação em Direito da Universidade de São Paulo, São Paulo - SP, 2007. 
insculpiu na lei processual penal, apresentando-se descrições resumidas, mas suficientes (crê-se) a que se chegue de forma natural às conclusões finais.

\subsection{As medidas assecuratórias do Código de Processo Penal}

A pretérita desatenção dada ao alcance patrimonial da persecução penal no cenário pátrio ${ }^{11}$, em comparação com a relevância atual dos instrumentos de constrição de bens e valores manejados na prática, fica evidente com o tratamento dado pelo CPP às ditas medidas assecuratórias disciplinadas nos seus arts. 125 a 144-A.

Explica-se: muitas vezes as medidas instrumentais aplicadas na fase investigatória ou ao longo do processo, visando assegurar bens destinados à reparação de danos e/ou ao perdimento de proventos do crime, não tomam a forma estrita das medidas previstas no CPP. Com crescente frequência, tem-se visualizado a aplicação de medidas amorfas, seguindo linhas práticas do processo civil ou outros diplomas legais, que priorizam o bloqueio de valores em contas, poupanças e fundos de investimentos (v.g. via sistema Bacenjud), ou mesmo um bloqueio de bens genérico que tampouco se amolda aos instrumentos específicos que serão descritos em linhas breves abaixo.

Primeiro, necessário indicar de plano que as medidas assecuratórias, ao contrário do que comumente se pensa, não se aplicam quanto (i) às coisas obtidas por meios criminosos, (ii) aos instrumentos de falsificação, contrafação e objetos falsificados e (iii) aos instrumentos utilizados na prática de crimes ou destinados a fim delituoso (art. 240, § 1. ${ }^{\circ}$, alíneas "b”, “c” e “d”, CPP).

Quanto a bens que se enquadrem nessas hipóteses - atente-se para o caráter aberto da terceira - , caberá a medida de busca e apreensão ${ }^{12}$, prevista nos arts. 240 a 250 do CPP. Também é por meio desse

11 "Não houve tratamento técnico aos institutos no processo penal, na medida em que estão no Código como um misto de sequestro e arresto." (NICOLLIT, A. Op. cit., p. 896).

12 DOTTI, René Ariel. Curso de direito penal: parte geral. 6. ed. São Paulo: RT, 2018. p. 715. 
instrumento que se dará a apreensão de objetos que de qualquer forma auxiliem na elucidação dos fatos (art. 240, § 1. , alíneas "e", "f" e "h", CPP). Portanto, em se tratando de coisa - ou mesmo valor - que consista em instrumento ou produto do crime, ou mesmo objeto relevante para a instrução, aplicar-se-á a busca e apreensão. ${ }^{13}$

Note-se, portanto, que, com base nessa premissa, fica claro que o âmbito de aplicabilidade das medidas assecuratórias propriamente ditas - ou típicas - é limitado a bens que não possuam relação direta ou imediata com o fato delituoso, pois nesse caso seria cabível a busca e apreensão ${ }^{14}$ (exceto quanto a bens imóveis, naturalmente).

A primeira medida assecuratória típica é o sequestro, ao qual o CPP dedica, basicamente, os arts. 125 a 132. A principal hipótese de cabimento é no tocante aos "bens imóveis, adquiridos pelo indiciado com os proventos da infração, ainda que já tenham sido transferidos a terceiro" (art. 125), desde que haja "indícios veementes da proveniência ilícita dos bens” (art. 126). Denote-se então que, para decretação do sequestro, será necessário evidenciar indícios veementes de que os bens foram adquiridos com proventos da infração, consistindo, portanto, em provento indireto da atividade criminosa. Ainda, no art. 132, prevê-se a possibilidade de decretação de sequestro de bens móveis, acaso demonstrados os mesmos indícios veementes de proveniência ilícita e (condição cumulativa) não seja aplicável a medida de busca e apreensão. ${ }^{15}$

A finalidade imediata desse instrumento é assegurar a decretação final de perdimento dos bens (mais sobre isso será oportunamente aduzido), conforme previsto no art. 133, caput, do CPP. ${ }^{16}$ Já o objetivo mediato é a reparação do dano causado a terceiro, conforme estabelecido no $\S 1 .^{\circ}$, sendo que "será recolhido aos cofres públicos o que não couber ao lesado ou a terceiro de boa-fé". Por brevidade, e considerado o foco que será desenvolvido nas seções adiante, as demais previsões legais referentes

13 NICOLLIT, A. Op. cit., p. 900-901.

BA tavo Henrique (coord.). Código de Processo Penal comentado. 2. ed. São Paulo: RT, 2019. p. 371. 
ao sequestro, tais quais a autorização de uso pelos órgãos públicos (art. 133-A, CPP), não serão abordadas.

A segunda modalidade específica trazida pelo CPP é a hipoteca legal de bens imóveis, especificamente destinada a satisfazer a reparação dos danos causados ao ofendido ${ }^{17}$, e dependente de "certeza da infração e indícios suficientes da autoria" (art. 134, CPP). Diferentemente do sequestro, tal medida incide sobre patrimônio lícito. ${ }^{18}$

A medida depende de iniciativa do ofendido, ou do Ministério Público, acaso haja interesse da Fazenda Pública ou em substituição ao ofendido (em caso de hipossuficiência - art. 142, CPP), mediante requerimento no qual será estimado o dano causado (art. 135, CPP).

Por fim, o arresto pode se dar subsidiariamente à hipoteca legal, sobre bens móveis, se o responsável não possuir bens imóveis ou o valor desses não for suficiente (art. 137, CPP), ou previamente à hipoteca legal, cuja especialização e inscrição, não raro, demanda mais tempo ${ }^{19}$.

Com essa descrição sumária das medidas trazidas pelo Código de Processo Penal, já se faz possível compreender os limites que serão descritos abaixo.

\subsection{PREVISÕES EM LEGISLAÇÃo EXTRAVAGANTE}

A patrimonialização do direito penal também é vista em leis penais especiais, situações em que o legislador prevê novas formas de dispor do patrimônio do investigado ou do acusado - ou, no mínimo, relembra o aplicador acerca da existência e possibilidade de aplicação das medidas já descritas no CPP.

Na Lei n. ${ }^{\circ} 11.343$, de 2006, que tutela o combate ao tráfico ilícito de entorpecentes, o art. 60 descreve, talvez de forma desnecessária, que são aplicáveis as medidas previstas nos arts. 125 e seguintes do CPP,

17 Ibid., p. 373.

18 "Enquanto o sequestro visa a indisponibilidade dos bens adquiridos com a prática do crime, portanto bens ilícitos, a hipoteca legal busca a constrição judicial dos bens de origem lícita, sem relação alguma com o crime." (LINHARES, S. C. Op. cit., p. 108).

19 Ibid., p. 111. 
no tocante a bens, direitos ou valores que "sejam produto do crime ou constituam proveito" do tráfico ilícito e outros tipos penais previstos pelo diploma.

Os demais dispositivos - do art. 60-A a 64 - dispõem principalmente acerca da conservação, da destinação, da alienação antecipada e da utilização dos bens apreendidos, e não propriamente de novas formas de medidas assecuratórias que não aquelas já abordadas acima. Ponto relevante é a recente (por meio da Lei n. ${ }^{\circ}$ 13.886, de 2019) previsão, no art. 63-F, de espécie de perdimento alargado de bens em caso de ser aferida "diferença entre o valor do patrimônio do condenado e aquele compatível com o seu rendimento lícito”. Como será mencionado abaixo, previsão semelhante também foi adicionada ao CP (art. 91-A).

A Lei de Lavagem de Dinheiro (Lei n. ${ }^{0} 9.613$, de 1998) também reafirma, em seu art. $4 .^{\circ}$, o cabimento de medidas assecuratórias- sem especificar quais - quanto a "bens, direitos ou valores do investigado ou acusado, ou existentes em nome de interpostas pessoas, que sejam instrumento, produto ou proveito dos crimes previstos nesta Lei”. O § $4{ }^{\circ}$ do art. descrito reitera ainda o cabimento das medidas assecuratórias como forma de garantir a "reparação do dano decorrente da infração penal antecedente ou da prevista nesta Lei ou para pagamento de prestação pecuniária, multa e custas".

No art. 7. ${ }^{\circ}$, encontra-se a previsão do perdimento de bens, direitos e valores "relacionados, direta ou indiretamente, à prática dos crimes" previstos na Lei em comento, aparentemente permitindo o alargamento da decretação de perdimento trazida no $\mathrm{CP}^{20}$. Os demais dispositivos, semelhantemente à Lei n. ${ }^{\circ} 11.343$, discorrem principalmente acerca da alienação e da destinação dos bens e valores apreendidos, aparentemente sem criar nova medida que não as gerais (acima).

Considerando não ser o foco do presente trabalho, ora não se adentrará nas previsões específicas trazidas nessas duas leis quanto aos bens e valores apreendidos.

Curiosamente, a Lei n. ${ }^{0} 12.850$, de 2013, que trata das organizações criminosas e das medidas de criminalização e investigação contra elas cabíveis, não traz em seu bojo dispositivos que sequer façam menção a

20 Nesse sentido, v. LOPES, J. F. M. Op. cit., p. 218. 
medidas assecuratórias, à reparação do dano e ao perdimento de bens e valores, salvo no art. $4^{\circ}$, inciso IV, em que se estabelece a "recuperação total ou parcial do produto ou do proveito das infrações penais praticadas pela organização criminosa" como requisito de perdão judicial ou redução da pena. A doutrina especializada já identificou, quanto a isso, a perda da oportunidade de conferir disciplina legal mais eficiente nesse ponto. ${ }^{21}$

No mais, a Lei não trata de quaisquer medidas destinadas à apreensão de bens ou valores, tampouco da reparação de danos causados ou perdimento de enriquecimento ilícito. Isso significa que, mesmo em se tratando de organizações criminosas e dos processos delas decorrentes, os meios de constrição patrimonial aplicáveis são — ou devem ser — aqueles previstos no CPP.

\section{Referibilidade Material das Medidas Assecuratórias}

A operacionalização das medidas assecuratórias descritas na seção acima só pode ser corretamente compreendida e efetivada com respeito aos limites estabelecidos pelo legislador acaso se retroceda a análise para um ponto elementar precedente: os efeitos patrimoniais da condenação penal. ${ }^{22}$

A bem da verdade, o escopo do tema dos efeitos patrimoniais da condenação penal é demasiadamente amplo, e marcado por divergências que, por óbvio, não poderiam ser satisfatoriamente abordadas - mesmo em resumo - no presente trabalho. Como exemplo, pode-se mencionar o possível bis in idem entre as sanções pecuniárias estabelecidas na seara penal, condenação à reparação de danos, e sanções aplicadas na esfera

${ }^{21}$ V. LOPES, J. F. M. Op. cit., p. 235.

22 "Cada um dos efeitos da condenação - pessoal e patrimonial - conta com medida cautelar, prevista no Código de Processo Penal, destinada a acautelá-la no curso da persecução penal." (SAAD, Marta. Prisão processual para recuperação de ativos: uma prática desfuncionalizada. In: MALAN, Diogo; BADARÓ, Gustavo; ZILLI, Marcos; MOURA, Maria Thereza Rocha de Assis; SAAD, Marta; MORAES, Maurício Zanoide de (org.). Processo penal humanista: escritos em homenagem a Antonio Magalhães Gomes Filho. Belo Horizonte: D’Plácido, 2019. p. 267). 
administrativa em decorrência de fatos que também foram objeto de escrutínio no juízo criminal. ${ }^{23}$

Contudo, algumas breves considerações sobre a natureza e características de dois dos principais efeitos (aqui em sentido lato) da sentença condenatória se fazem necessárias para que se chegue a um dos pontos nevrálgicos do estudo. Isso porque, como se delineou acima, a ratio que determina o cabimento e o procedimento de cada medida assecuratória se orienta conforme o objetivo final visado. ${ }^{24}$

Dessa forma, as peculiaridades desse objetivo final condicionam — ou melhor, devem condicionar - a operacionalização dos instrumentos processuais identificados acima. ${ }^{25}$

Trata-se da obrigação de reparação do dano causado e do perdimento do produto ou proventos do crime, consequências que, conforme se viu na seção anterior, figuram como principais objetivos das medidas assecuratórias. ${ }^{26}$

23 Sobre esse ponto, ver: COSTA, Helena Regina Lobo da. Direito Penal Econômico e Direito Administrativo Sancionador: ne bis in idem como medida de política sancionadora integrada. Tese (Livre Docência). Faculdade de Direito da Universidade de São Paulo, São Paulo - SP, 2013.

24 "A referibilidade, como se pode verificar, revela-se como instrumento de aferição dos limites da medida constritiva patrimonial, a denotar sua importância” (MAGRIARELLI, Filipe Henrique Vergniano. Cooperação jurídica internacional em matéria penal e as medidas cautelares patrimoniais. Dissertação (Mestrado em Direito), Programa de Pós-Graduação da Faculdade de Direito da Universidade de São Paulo, São Paulo - SP, 2014. p. 68).

25 “Os efeitos automáticos da decisão condenatória, de caráter real, também são assegurados, no curso do processo penal, por meio de medidas cautelares patrimoniais, as quais não podem ser tomadas de forma desmotivada, porque devem obedecer a pressupostos e requisitos delimitados, em respeito à garantia da presunção de inocência ou proibição de prévia consideração da culpabilidade." (SAAD, M. Op. cit. (2019), p. 270).

26 "Há, entre as medidas cautelares previstas no CPP, duas finalidades distintas: a medida de sequestro destina-se a assegurar o cumprimento do efeito da condenação consistente na perda do produto do crime. Já a inscrição e registro da hipoteca legal e o arresto prévio visam à reparação do dano causado pelo delito. Enquanto a primeira medida impede o lucro ilícito, as duas últimas asseguram a reparação do prejuízo causado à vítima." (BADARÓ, Gustavo Henrique. Processo penal. 4. ed. São Paulo: RT, 2016. p. 1113). 
Embora o perdimento e a obrigação de reparar danos figurem como efeitos da condenação e constituam o principal fundamento para a incidência de medidas assecuratórias do processo penal ${ }^{27}$, a natureza jurídica dessas duas consequências patrimoniais da condenação penal é distinta. Por isso, as regras aplicáveis não são as mesmas. Confira-se.

\subsection{A OBRIGAÇÃO DE REPARAÇÃO DO DANO}

Resumindo-se ao elementar, pode-se dizer que a sentença penal condenatória declara a ocorrência de fato amoldado a um determinado tipo penal, bem como identifica o agente pessoal e subjetivamente responsável pela prática de tal ato, ao final condenando-lhe ao cumprimento das sanções previstas no preceito secundário do dispositivo incriminador. ${ }^{28}$ Quaisquer que sejam as penas aplicadas ao final, característica comum da sentença penal condenatória é declarar a ocorrência de um ato ilícito.

Considerando, na perspectiva de círculos concêntricos, que o fato delituoso que figura como objeto de conhecimento do processo penal e da sentença existe no ordenamento jurídico como espécie do gênero dos atos ilícitos (art. 186, CC), reconhece-se a incidência simultânea de dispositivos de natureza penal e de natureza civil, de modo que a prática do crime, comumente, ensejará responsabilização criminal e civil cumulativas ${ }^{29}$.

Enquanto as consequências de natureza penal estarão descritas e reguladas no $\mathrm{CP}$ e dispositivos incriminadores de legislação extravagante, as consequências civis da prática do fato delituoso (ato ilícito) serão regidas pelo CC. Dentre elas, a principal, provavelmente, é a obrigação de reparar o dano ${ }^{30}$, estabelecida no art. 927 do CC.

27 No mesmo sentido, v. MAGRIARELLI, F. H. V. Op. cit., p. 56.

28 NICOLLIT, A. Op. cit., p. 941-943.

29 MAGRIARELLI, F. H. V. Op. cit., p. 59-60.

30 "A este respeito, o efeito de 'tornar certa a obrigação de indenizar o dano causado pelo crime' (inc. I do art. 91), não apresenta conteúdo penal, sendo um efeito civil da condenação penal”. (ZAFFARONI, Eugenio Raúl; PIERANGELI, 
Embora afirmar que a obrigação de reparar o dano causado pelo fato criminoso decorre da legislação civil e não propriamente da lei penal pareça equivocado, os próprios dispositivos do CP e do CPP que versam sobre - não estabelecem - a reparação do dano confirmam essa premissa. ${ }^{31}$

No art. 91, inciso I, do CP está previsto que um dos efeitos da condenação é "tornar certa a obrigação de indenizar o dano causado pelo crime”. Denote-se que a locução tornar certa a obrigação, em sentido técnico jurídico estrito, é consideravelmente diferente de condenar à reparação de danos. Significa dizer que a condenação criminal apenas confirma existência da obrigação - instituto jurídico regido pela lei civil - de reparar o dano, em vez de verdadeiramente condenar o agente à dita reparação. ${ }^{32} \mathrm{O}$ fato de comumente se utilizar em sentenças condenatórias construções frasais como "condeno o réu ao pagamento do valor de $\mathrm{X}$ a título de reparação de danos” não altera esse fato.

Isso também é confirmado pelo fato de o CPP, em seu art. 387, inciso IV, determinar ao juiz a fixação o valor mínimo para reparação do dano na sentença. A previsão do ato de fixar $^{33}$ valor mínimo na sentença condenatória, relegando a efetiva definição do valor total do dano e a execução ao juízo cível ${ }^{34}$, se coaduna ao acima exposto.

Em suma, a obrigação de reparar o dano decorrente do crime obedece à legislação civil ${ }^{35}$. O estabelecimento dessa premissa é necessário para o raciocínio que será apresentado na seção 3 adiante.

José Henrique. Manual de direito penal brasileiro: parte geral. 11 ed. São Paulo: RT, 2015. p. 729).

31 MARTINELLI, João Paulo Orsini; BEM, Leonardo Schmitt de. Lições fundamentais de direito penal: parte geral. 3. ed. São Paulo: Saraiva, 2018. p. 962-963. BADARÓ, Gustavo Henrique. Processo penal. 4. ed. São Paulo: RT, 2016. p. 214.

"Não há dúvida de que temos aqui um conteúdo material, mas não de direito penal e sim de direito civil. Vale dizer: o legislador reconheceu o dever do juiz de fixar o valor mínimo da indenização e esta indenização é de natureza civil, afastando-se, portanto do antigo sistema da confusão." (DEZEM, Guilherme Madeira. Curso de processo penal. 5. ed. São Paulo: RT, 2019. p. 348).

34 NICOLLIT, A. Op. cit., p. 374-375.

35 ZAFFARONI, E. R.; PIERANGELI, J. H. Op. cit., p. 746-765. 


\subsection{Perdimento do produto e proventos do cRime}

O segundo efeito patrimonial da sentença condenatória que enseja a referibilidade das medidas assecuratórias - em especial o sequestro - é o perdimento do produto e dos proventos do crime.

A previsão legal se dá no art. 91, inciso II, alínea "b", do CP, incidindo sobre o "produto do crime ou de qualquer bem ou valor que constitua proveito auferido pelo agente com a prática do fato criminoso". Enquanto o produto do crime consiste no proveito direto e imediato decorrente da prática ilícita - v.g. a coisa alheia móvel subtraída no crime de roubo, ou o valor ilícito recebido como exaurimento da corrupção passiva -, o proveito auferido se refere ao lucro (em sentido lato) gerado a partir do produto do crime - ou seja, benefício indireto ${ }^{36}$. Poder-se-ia falar, por exemplo, na renda gerada a partir do investimento dos valores ilícitos recebidos a título de corrupção passiva.

O perdimento também pode recair sobre "bens ou valores equivalentes ao produto ou proveito do crime quando estes não forem encontrados ou quando se localizarem no exterior" (art. 91, § 1. ${ }^{\circ}, \mathrm{CP}$ ), o que pressupõe que tais bens tenham sido, ao menos, identificados ${ }^{37}$. O $§ 2 .^{\circ}$ do art. 91, por sua vez, estende a aplicabilidade das medidas assecuratórias do CPP a "bens ou valores equivalentes do investigado ou acusado para posterior decretação de perda".

Essa modalidade de confisco "por equiparação" (art. 91, §§ 1. ${ }^{\circ} \mathrm{e}$ $\left.2 .^{\circ}\right)$ pode dificultar a visualização exata das finalidades buscadas, enfraquecendo, por consequência, os limites de alcance quanto ao patrimônio lícito do acusado/investigado.

Porém, a leitura atenta dos dispositivos indica que essas modalidades também se limitam ao efetivo enriquecimento ilícito auferido pelo acusado (o que difere de dano causado a terceiro), ante a previsão expressa do cabimento quanto a bens equivalentes ao "produto ou proveito do crime”. Não se elimina, portanto, a necessidade de demonstração, por

36 Ibid., p. 730. No mesmo sentido, v. ESSADO, Tiago. A perda de bens e o novo paradigma para o processo penal brasileiro. Dissertação - Mestrado em Direito - Programa de Pós-graduação em Direito da Universidade de São Paulo, São Paulo - SP, 2014. p. 24 e 48.

37 ESSADO, T. Op. cit., p. 49-50. 
parte do Ministério Público e do juiz, de que houve enriquecimento ilícito e de quanto se acresceu ilicitamente ao patrimônio do acusado.

Lembre-se, ainda, que o mesmo artigo também prevê o perdimento dos instrumentos do crime (art. 91, II, “a”, CP). Porém, considerando que o presente trabalho tem como foco as medidas assecuratórias - sequestro, hipoteca legal e arresto - que guardam relação de referibilidade com os proventos, não se tratará especificamente da perda dos instrumentos, visto que quanto a esses aplica-se a medida de busca e apreensão (cf. 1.1, acima).

Importante apontar, também, que a reforma operada na legislação penal e processual penal com a Lei "Anticrime" criou nova previsão de perda de bens "correspondentes à diferença entre o valor do patrimônio do condenado e aquele que seja compatível com o seu rendimento lícito", no art. 91-A do CP.

Essa modalidade, comumente referida como confisco alargado, é aplicável quanto os crimes apenados com pena máxima superior a 6 (seis) anos de reclusão, e, similarmente à modalidade de confisco "por equiparação" acima mencionada, baseia-se em uma presunção de enriquecimento ilícito. Isso porque a decretação de perdimento incidirá sobre o que seria a "diferença entre o valor do patrimônio do condenado e aquele que seja compatível com o seu rendimento lícito". Para que haja decretação, deverse-á demonstrar, no mínimo, que há disparidade objetiva entre o patrimônio possuído pelo acusado, ainda que a origem não seja perfeitamente identificada, e o que seria seu real patrimônio, com base em seu rendimento lícito.

Cabe reforçar que o fundamento para a criação dessa medida no CP tem por objeto evitar o "enriquecimento ilícito" decorrente da prática do crime, o que difere de "dano causado pelo crime”. Não há, porém, medida assecuratória destinada a tornar indisponível antes da condenação a "diferença entre o valor do patrimônio do condenado e aquele que seja compatível com o seu rendimento lícito”. Essa modalidade merece tratamento cuidadoso especial ${ }^{38}$, e, por não estar associada a qualquer medida assecuratória do CPP, não será o objeto de reflexão no presente texto. ${ }^{39}$

38 V. SANTOS, Juarez Cirino dos. Reflexões sobre o confisco alargado. Boletim IBCCRIM. v. 277, a. 23, p. 23-24, 2015.

39 Para considerações críticas a respeito da perda alargada, v. LUCCHESI, Guilherme Brenner. Confisco alargado: análise das medidas para recuperação 
O perdimento decorrente da sentença penal condenatória possui natureza jurídica diversa da obrigação de indenizar o dano decorrente do crime, ainda que esteja previsto no mesmo dispositivo do CP. A consequência tratada na subseção acima consiste em obrigação de natureza civil decorrente de ato ilícito, que se faz declarada na decisão condenatória, enquanto o efeito sobre o qual aqui se trata consiste verdadeiramente em consequência de natureza penal. ${ }^{40}$

Evitando adentrar no tormentoso tema do conceito da sanção penal, o que certamente não é o foco visado (e nem se poderia fazê-lo de forma adequada em trabalho breve tal qual o presente), basta ter-se em mente que a própria Constituição prevê o perdimento como efetiva pena ( $\operatorname{art} .5^{\circ}$, XLVI, "b" ${ }^{41}$ ), que será decretada (note-se: não declarada ou tornada certa - diferença terminológica relevante do aspecto técnico-jurídico) pelo juiz criminal na sentença condenatória, de forma comparável à perda dos direitos políticos. Tal forma de extinção do direito de propriedade não encontra previsão na legislação civil ${ }^{42}$, como acontece com a obrigação de reparar o dano.

Isso significa dizer que o perdimento é instituto propriamente penal $^{43}$, decorrente da lei penal em sentido estrito e, portanto, sujeito às

de bens de origem ilícita na experiência comparada americana. In: LEITE, Alaor; TEIXEIRA, Adriano (org.) Crime e política: Corrupção, financiamento irregular de partidos políticos, caixa dois eleitoral e enriquecimento ilícito. São Paulo: FGV Editora, 2017. p. 425-428. Sobre a alteração do CP pela Lei "Anticrime”, v. MENDES, Tiago Bunning; LUCCHESI, Guilherme Brenner. Lei Anticrime: (Re)forma penal e a aproximação de um sistema acusatório? Florianópolis: Tirant Lo Blanch, 2020 (no prelo).

ZAFFARONI, E. R.; PIERANGELI, J. H. Op. cit., p. p. 729. Em posição diversa, embora sem atribuir natureza cível à perda, que seria "efeito extrapenal genérico da condenação”, v. CORRÊA JUNIOR, A. Op. cit., p. 38. Para uma análise detalhada do dispositivo em comento, v. Ibid., p. 147-154. Interessante ressalva pode ser feita no tocante aos bens auferidos com a prática do tráfico ilícito de entorpecentes, cuja perda em favor da União encontra previsão específica no art. 243 da Constituição da República.

43 Há posições divergentes na doutrina: “A perda de bens é um instituto de direito material. Consiste num efeito de natureza patrimonial decorrente da condenação penal. A natureza jurídica da perda de bens é assunto controvertido, tanto no Brasil como em outros países. No Brasil, os principais posicionamentos sobre o tema são os seguintes: a) natureza penal; b) natureza extrapenal 
regras e princípios aplicáveis a esse ramo específico do ordenamento pátrio. Essa constatação é elementar para as conclusões que se visa apresentar na seção adiante.

\section{Os Limites Subjetivos do Perdimento de Bens}

Na seção acima, estabeleceu-se premissa dupla - como dois lados de uma mesma moeda - que encampa o raciocínio a ser desdobrado nesta seção. Tal é que a obrigação de reparar o dano consiste em instituto que obedece às regras do direito civil, enquanto o perdimento de bens consiste em efeito propriamente penal, e por isso sujeito às regras e princípios específicos desse ramo do ordenamento.

A diferença do regime de princípios e regras aplicáveis a essas duas “consequências" da condenação enseja mudanças no tocante à extensão subjetiva de tais figuras, conforme se expõe abaixo.

\subsection{A SOLIDARIEDADE DA OBRIGAÇÃO DE REPARAR O DANO}

Dentre as disposições do CC, tem-se nos arts. 264 a 285 as regras aplicáveis às obrigações solidárias, sendo aquelas em que "na mesma obrigação concorre mais de um credor, ou mais de um devedor, cada um com direito, ou obrigado, à dívida toda" (art. 264).

De suma importância - para o presente trabalho e para o regime jurídico civil em geral - é a previsão do dispositivo seguinte, por força do qual se estabelece que "a solidariedade não se presume; resulta da lei ou da vontade das partes”. Isso significa dizer que, em se tratando de obrigação decorrente de lei (diga-se, não oriunda de contrato), só haverá solidariedade se houver previsão legal específica e expressa nesse sentido.

Para o que demais interessa ao presente trabalho, encontra-se no art. 275 do CC a definição da solidariedade passiva, regra conforme a qual o credor da obrigação "tem direito a exigir e receber de um ou de alguns dos devedores, parcial ou totalmente, a dívida comum”.

genérica; c) natureza civil; d) natureza reparatória e preventiva." (ESSADO, T. Op. cit., p. 18). Para Essado, a perda de bens é efeito civil da condenação penal. 
Por fim, o dispositivo elementar que determina a solidariedade da obrigação de reparar o dano se encontra no art. 942 do CC, no qual se lê que "os bens do responsável pela ofensa ou violação do direito de outrem ficam sujeitos à reparação do dano causado; e, se a ofensa tiver mais de um autor, todos responderão solidariamente pela reparação".

Concatenando vários dos dispositivos abordados no texto, sintetiza-se que o ato ilícito (art. 186, CC) que tomar forma de crime ensejará a obrigação de reparar o dano (art. 927, CC) ${ }^{44}$, à qual responderão solidariamente todos os autores (art. 942, CC). Com a sentença penal condenatória, torna-se certa esta obrigação (art. 91, I, CP) que, diante das regras que regem a responsabilidade civil, pode ser exigida de quaisquer dos condenados. Ver-se-á abaixo que o perdimento não obedece à mesma lógica.

\subsection{INAPLICABILIDADE DA SOLIDARIEDADE AO PERDIMENTO DO ENRIQUECIMENTO ILÍCITO}

Em sequência a tudo que se expôs acima a respeito da natureza solidária da obrigação de reparar o dano causado com a prática da conduta delituosa, tem-se, em sentido oposto, que a decretação de perdimento de bens pelo Juízo criminal não pode ultrapassar os limites personalíssimos da pena. ${ }^{45}$

Já se descreveu na subseção 2.2. acima, embora de forma breve, que a decretação de perdimento dos produtos e proventos do crime (art. 91, § 1. ${ }^{\circ}$, II, “a” e “b”, CP) consiste em verdadeira sanção decorrente da condenação criminal, de forma alguma se podendo confundir, no tocante à sua natureza, com a obrigação de reparar o dano.

${ }^{44}$ MARTINELLI, J. P.; BEM, L. S. Op. cit., p. p. 962-963.

45 "Não existe fundamento humano, social, e ético para que o sacrifício da pena seja também imposto aos parentes e amigos do responsável pelo fato punível." (DOTTI, R. A. Op. cit., p. 668). No mesmo sentido: "A primeira garantia do princípio de culpabilidade diz respeito à intranscendência da pena, ou seja, a responsabilidade penal não poderá ultrapassar a pessoa do autor do crime. Proíbe-se, em termos simples, que a pena recaia sobre uma pessoa diferente da que praticou o fato que lhe serve de fundamento." (MARTINELLI, J. P.; BEM, L. S. Op. cit., p. 250). 
Tal forma de extinção do direito de propriedade ${ }^{46}$, portanto, deverá se conformar a princípios e regras específicos do ordenamento penal, que não necessariamente se aplicam às normas do direito civil - e vice-versa.

Com base nessa constatação, deve-se concluir que os dispositivos do CC que preveem a solidariedade da obrigação de reparar o dano causado pelo ato ilícito são inaplicáveis à decretação de perdimento de bens. Lembre-se: a previsão expressa do CC vige no sentido de que, afora obrigações contratuais, a solidariedade não se presume. E, como se viu, no que diz respeito aos efeitos patrimoniais da condenação penal, a solidariedade passiva está estabelecida de forma expressa na lei civil apenas no tocante à reparação de danos. O mesmo não ocorre quanto ao perdimento de bens, que é efeito patrimonial propriamente penal da condenação criminal.

Não somente, em se tratando de sanção penal propriamente dita, vige o princípio da intranscendência, insculpido no inciso XLV do art. 5. ${ }^{\circ}$ da Constituição, o qual determina de forma clara que "nenhuma pena passará da pessoa do condenado".

Nas exceções estabelecidas pelo próprio dispositivo, tem-se que poderão "a obrigação de reparar o dano e a decretação do perdimento de bens ser, nos termos da lei, estendidas aos sucessores e contra eles executadas, até o limite do valor do patrimônio transferido". Nenhuma dessas ressalvas autorizadas pelo Constituinte insculpe a solidariedade no tocante ao perdimento. Este não é alcançado pela previsão expressa na lei civil de solidariedade quanto à reparação. E mais: a ressalva em si, quanto ao perdimento, confirma que a extensão para além do condenado somente poderá se dar nos limites do patrimônio transferido, o que pressupõe ter havido efetivo repasse de bens e/ou valores decorrentes da prática criminosa.

Retornando-se às hipóteses legais de perdimento do CP (art. 91), vê-se que no que diz respeito aos instrumentos do crime, as coisas a serem perdidas serão específicas, determinadas e estarão ou em poder do condenado ou com quem dele as tenha recebido. Apreender-se-á o tal

46 Pode-se cogitar, com ressalvas, que nem tudo que possa vir a ser alvo de perdimento realmente integrava o patrimônio do condenado, v.g. eventual instrumento de crime que tão somente estava em posse do agente. 
instrumento, mediante busca e apreensão, e decretar-se-á o perdimento, quem quer seja o seu atual detentor. ${ }^{47}$

Já no tocante ao produto do crime ou qualquer bem ou valor que constitua proveito auferido em decorrência do ilícito, somente se poderá decretar o perdimento contra o próprio autor do fato delituoso ou, quando muito, contra quem tiver recebido bens ou valores provenientes da prática do ilícito. Nesse último caso, o perdimento estará limitado ao valor transferido. O perdimento dos proventos do crime, naturalmente, exige que tenha havido enriquecimento ilícito por parte daquele que virá a ser alvo da decretação.

Conjugando-se (i) a limitação da solidariedade passiva à obrigação de reparação do dano, (ii) o princípio da intranscendência das penas e (iii) os limites claros das exceções constitucionais ao referido princípio, tem-se por certo que a decretação de perdimento dos proventos do crime não pode se dar de forma solidária entre os coautores de um ilícito penal e/ou entre corréus em um mesmo feito, ainda que todos venham a ser condenados.

Em suma, diferentemente da obrigação solidária de reparar o dano causado, os limites da decretação de perdimento deverão obedecer estritamente ao exato montante do enriquecimento ilícito que cada autor do fato criminoso auferiu, admitindo-se extensão tão somente se houve transferência de proventos entre eles. Não se poderá, dessa forma, decretar o perdimento de bens e valores contra um determinado réu condenado, a fim de punir eventual enriquecimento ilícito auferido por outro réu.

\section{Solidariedade nas Medidas Assecuratórias}

A partir das duas premissas demonstradas na seção 3, ora podese traçar o caminho inverso, retornando-se às medidas assecuratórias patrimoniais descritas na seção 1, a fim de que se estabeleçam a elas os limites aplicáveis conforme a finalidade, dentre aquelas descritas na seção 2, com a qual forem implementadas.

47 Evitou-se propositadamente utilizar o termo proprietário, dado o caráter problemático do direito de propriedade quanto aos instrumentos do crime e coisas cujo fabrico, alienação, uso, porte ou detenção constitua fato ilícito. 
No mais, após o que se expôs acima, pode-se solucionar os dois casos concretos formulados ao início.

\subsection{Solidariedade No ARRESTO E ESPECIALIZAÇÃo DE HiPOteCA LEGAL}

A hipoteca legal e o arresto referem-se à finalidade de reparação do dano causado - lembre-se a expressa legitimidade do ofendido bem como, de forma subsidiária, "as despesas processuais e as penas pecuniárias" (art. 140, CPP).

Considerando a finalidade específica dessas duas medidas, tem-se que quanto a elas aplicar-se-á o efeito da solidariedade, descrito na seção 3, de modo que o arresto e a hipoteca legal poderão recair sobre quaisquer bens de cada acusado até o limite de todo o dano causado pelo crime.

Ou seja: o valor máximo do dano poderá ser utilizado como parâmetro para fixação do valor para aplicação dessas medidas contra cada um dos codenunciados, de modo que um único acusado pode ter seu patrimônio - ainda que plenamente lícito - constrito no valor de todo o dano causado.

Em paralelo ao que se tem visto cotidianamente em processos criminais, em nenhum dos casos concretos houve a decretação de arresto ou hipoteca. Como já afirmado anteriormente, as peculiaridades referentes ao procedimento aplicável parecem fazer com que as autoridades públicas priorizem o sequestro e as medidas amorfas como bloqueio de valores e bens.

\subsection{SolidARIEDADE NO SEQUESTRO}

Já quanto ao sequestro, a situação é diversa do que se descreveu acima. Primeiro, porque a medida somente caberá quando presentes indícios veementes de que os bens foram adquiridos com proventos da infração. $\mathrm{O}$ primeiro limite advém da própria previsão de cabimento da medida, que se cinge aos bens que puderem ser alcançados pelo perdimento. No caso, esses serão os produtos e proventos ${ }^{48}$ da atividade criminosa (art. 91, II, CP).

48 Excetuam-se os instrumentos do crime, pois quanto a esses caberá não o sequestro, mas a busca e apreensão (art. 240, CPP). 
O sequestro não poderá ser aplicado, portanto, quanto a patrimônio lícito e que não decorra, na forma de provento indireto, de valor ou de proveito obtido com a prática delituosa.

O segundo limite, que se soma ao primeiro e consiste no ponto focal do presente artigo, refere-se à inaplicabilidade da solidariedade no tocante ao enriquecimento ilícito (seção 3). Como já se demonstrou acima, diferentemente da obrigação solidária de reparar o dano causado, os limites da decretação de perdimento devem obedecer estritamente ao exato montante do enriquecimento ilícito que cada autor do fato criminoso auferiu.

Por conseguinte, considerando que a finalidade do sequestro está relacionada ao perdimento, tem-se que o sequestro somente poderá incidir sobre instrumentos, produtos e proventos da atividade criminosa e no estrito limite do enriquecimento ilícito auferido pelo agente.

Essa medida não poderá ser aplicada, portanto, em limite superior ao que cada coautor tenha percebido como enriquecimento ilícito próprio. Em suma, o sequestro não poderá ser aplicado conforme a lógica da solidariedade, sendo inviável que se aplique tal constrição em quantum superior ao que o agente efetivamente percebeu como produto e proventos do crime.

Retomemos os casos formulados na Introdução.

No Caso 1, a medida atípica de bloqueio de valores, embora comum, não está prevista no CPP. Entendemos que, em se tratando de medida cautelar, deve-se obedecer ao princípio da legalidade ${ }^{49}$, de modo a aplicar alguma medida assecuratória típica, i.e. sequestro, hipoteca legal e arresto. Desse modo, descabida a constrição patrimonial genérica. No mais, quanto aos valores em si, tem-se que os $\mathrm{R} \$ 100.000,00$ recebidos como vantagem indevida consistiram em enriquecimento ilícito aproveitado tão somente por C, o qual, por isso, poderia ser alvo de sequestro. Não houve

49 "Constituído o princípio da legalidade, por outro lado, a mais sólida garantia das pessoas contra possíveis arbítrios do Estado, não se vê porque não haja ele de estender-se, na medida imposta pelo seu conteúdo de sentido, ao processo penal, cuja regulamentação pode a todo momento pôr em grave risco a liberdade das pessoas" (FIGUEIREDO DIAS, Jorge de. Direito Processual Penal. Coimbra: Coimbra Editora, 2004. p. 96-97. No mesmo sentido, especialmente quanto às medidas assecuratórias, v. ESSADO, T. Op. cit., p. 38. 
demonstração de dano pecuniário causado ao Estado, à coletividade ou a qualquer vítima determinada, de modo que não haveria que se falar em reparação de dano ou, por isso, em solidariedade. Por fim, como A e $B$ não tiveram enriquecimento ilícito demonstrado, não poderiam ter seus respectivos patrimônios alcançados por medida assecuratória, por não haver previsão legal - ainda que, caso condenados, pudessem vir a sofrer perda alargada (art. 91-A) se a licitude da origem de seus bens não for demonstrada.

Quanto ao Caso 2, tendo sido causado prejuízo de $\mathrm{R} \$ 100.000,00$, $\mathrm{X}$ e Y responderão solidariamente quanto a esse total, de forma que as medidas assecuratórias poderiam abranger tal valor para ambos, independentemente de quanto cada um auferiu como proveito do crime. Apesar disto, considerando-se que o sequestro se aplica quando houver "indícios de proveniência ilícita", os valores bloqueados nas contas de $\mathrm{X}$ e $\mathrm{Y}$ não poderiam ser alcançados; o veículo adquirido por $\mathrm{X}$ com os $\mathrm{R} \$ 70.000,00$ que auferiu com o crime poderia ser objeto de sequestro, desde que identificada previamente a proveniência ilícita do valor usado na aquisição. Por fim, quanto à maleta que continha os $\mathrm{R} \$ 30.000,00$ que couberam a Y, caberia medida de busca e a apreensão, que, por manejo atécnico da medida de sequestro, não veio a ser realizada.

\section{Conclusão}

Como visto, o sequestro, medida assecuratória utilizada com frequência crescente no paradigma atual de patrimonialização do direito penal, deve se ater ao limite do efetivo enriquecimento ilícito que o sujeito alvo obteve. Não se pode perverter tal modalidade cautelar patrimonial, por ser ela aparentemente mais célere e simples que a hipoteca legal e o arresto (que pressupõe posterior especialização de hipoteca), a fim de alcançar patrimônio desrelacionado à prática delituosa e/ou para punir um agente pelo enriquecimento ilícito de outros.

Tampouco se pode, de forma estranha às medidas assecuratórias expressamente previstas na lei processual penal, lançar mão de medidas amorfas que visem constringir bens de forma indistinta e ilimitada, sob a premissa de que o crime não pode compensar. A premissa não está 
equivocada, mas tampouco o está a afirmação de que os agentes encarregados da persecução penal devem respeitar os limites da lei.

Espera-se que, após a argumentação no presente texto, essas constatações pareçam por demais óbvias. Quiçá, assim devesse ser. Porém, o cenário complexo da persecução penal voltada aos megaprocessos ${ }^{50} \mathrm{e}$ às organizações criminosas vem ensejando - aos órgãos de investigação, ao Ministério Público, aos juízes e às defesas - sérias dificuldades (ou mesmo desinteresse) em delimitar estritamente o alcance do confisco patrimonial que se dará sob a forma de perdimento de bens.

As dificuldades práticas e teóricas a serem enfrentadas hoje não mais se manifestam em casos como roubos residenciais perpetrados por diversos autores com divisão de funções e repartição de lucros. Agora se lida com atos de corrupção imputados a organizações criminosas não raro integradas por dezenas de agentes, com atuação espraiada na máquina pública e/ou estruturada em empresas atuantes em vários países, por anos a fio.

Assim, as linhas de separação, não somente da autoria e da participação como das repercussões patrimoniais de tais delitos, no tocante aos danos causados e ao enriquecimento ilícito dos envolvidos, não mais se visualizam com facilidade. Isso, por sua vez, reflete no cabimento de toda sorte de medidas processais e penas, aplicáveis na medida da culpabilidade de cada agente.

Por isso, as conclusões quanto ao perdimento e ao sequestro apresentadas acima, que poderiam (e até deveriam) parecer óbvias, nem sempre o são na prática. Isso só se agrava ao levar em consideração o escopo dos megaprocessos e das inúmeras ações penais deles decorrentes, cenário em que se lida com dezenas de agentes delituosos e cifras bilionárias de danos causados, que nem sempre correspondem ao enriquecimento ilícito auferido.

Considerando que o ordenamento penal democrático deve obedecer a limites previstos na Constituição e na lei penal em favor dos acusados, e não somente da sociedade vitimada - o que por vezes parece ser esquecido -, o alcance das medidas assecuratórias deve ser tecnicamente

${ }^{50}$ Acerca da expressão ver MALAN, Diogo Rudge. Megaprocessos e direito de defesa. Revista Brasileira de Ciências Criminais, São Paulo, n. 159, p. 45-67, set. 2019. 
definido, compreendido e aplicado de forma a compatibilizar a persecução e, simultaneamente, o respeito aos direitos fundamentais daquele que se vê como alvo do poder de punir.

\section{REFERÊNCIAS}

BADARÓ, Gustavo Henrique. Das Questões e Processos Incidentes. In: GOMES FILHO, Antonio Magalhães; TORON, Alberto Zacharias; BADARÓ, Gustavo Henrique (coord.). Código de Processo Penal comentado. 2. ed. São Paulo: RT, 2019. p. 317-398.

BADARÓ, Gustavo Henrique. Processo penal. 4. ed. São Paulo: RT, 2016.

CORRÊA JUNIOR, Alceu. Confisco penal: alternativa à prisão e aplicação aos delitos econômicos. São Paulo: IBCCRIM, 2006.

COSTA, Helena Regina Lobo da. Direito Penal Econômico e Direito Administrativo Sancionador: ne bis in idem como medida de política sancionadora integrada. Tese (Livre Docência). Faculdade de Direito da Universidade de São Paulo, São Paulo - SP, 2013.

DOTTI, René Ariel. Curso de direito penal: parte geral. 6. ed. São Paulo: RT, 2018. ESSADO, Tiago. A perda de bens e o novo paradigma para o processo penal brasileiro. Dissertação (Mestrado em Direito) - Programa de Pós-graduação em Direito da Universidade de São Paulo, São Paulo - SP, 2014.

FIGUEIREDO DIAS, Jorge de. Direito Processual Penal. Coimbra: Coimbra Editora, 2004.

LINHARES, Sólon Cicero. Confisco de bens: Uma medida penal, com efeitos civis contra a corrupção. São Paulo: RT, 2016.

LOPES, João Felipe Menezes. Confisco de bens como instrumento de combate à criminalidade organizada: análise dos regimes estrangeiros e de sua compatibilidade com o ordenamento jurídico brasileiro. Revista da AJUFE, São Paulo, v. 95, n. 2, p. 207-240, 2015.

LUCCHESI, Guilherme Brenner. Confisco alargado: análise das medidas para recuperação de bens de origem ilícita na experiência comparada americana. In: LEITE, Alaor; TEIXEIRA, Adriano (org.) Crime e política: Corrupção, financiamento irregular de partidos políticos, caixa dois eleitoral e enriquecimento ilícito. São Paulo: FGV Editora, 2017. p. 425-428. 
MAGRIARELLI, Filipe Henrique Vergniano. Cooperação jurídica internacional em matéria penal e as medidas cautelares patrimoniais. Dissertação (Mestrado em Direito), Programa de Pós-Graduação da Faculdade de Direito da Universidade de São Paulo, São Paulo - SP, 2014.

MALAN, Diogo Rudge. Megaprocessos e direito de defesa. Revista Brasileira de Ciências Criminais, São Paulo, n. 159, p. 45-67, set. 2019.

MARTINELLI, João Paulo Orsini; BEM, Leonardo Schmitt de. Lições fundamentais de direito penal: parte geral. 3. ed. São Paulo: Saraiva, 2018.

MENDES, Tiago Bunning; LUCCHESI, Guilherme Brenner. Lei Anticrime: (Re) forma penal e a aproximação de um sistema acusatório? Rio de Janeiro: LumenJuris, 2020 (no prelo).

NICOLLIT, André. Manual de processo penal. 7. ed. Belo Horizonte: D’Plácido, 2018.

RIOS, Rodrigo Sánchez; PUJOL, Luiz Gustavo. Confisco alargado: reflexões acerca de suas possibilidades no ordenamento jurídico brasileiro. Revista Brasileira de Ciências Criminais, São Paulo, v. 118, p. 123-158, jan.-fev. 2016.

SAAD GIMENES, Marta Cristina Cury. As medidas assecuratórias do Código de Processo Penal como forma de tutela cautelar destinada à reparação do dano causado pelo delito. Tese (Doutorado em Direito) - Programa de Pós-graduação em Direito da Universidade de São Paulo, São Paulo - SP, 2007.

SAAD, Marta. Prisão processual para recuperação de ativos: uma prática desfuncionalizada. In: MALAN, Diogo; BADARÓ, Gustavo; ZILLI, Marcos; MOURA, Maria Thereza Rocha de Assis; SAAD, Marta; MORAES, Maurício Zanoide de (org.). Processo penal humanista: escritos em homenagem a Antonio Magalhães Gomes Filho. Belo Horizonte: D’Plácido, 2019. p. 265-284.

SANTOS, Juarez Cirino dos. Reflexões sobre o confisco alargado. Boletim IBCCRIM. v. 277, a. 23, p. 23-24, 2015.

ZAFFARONI, Eugenio Raúl; PIERANGELI, José Henrique. Manual de direito penal brasileiro: parte geral. 11 ed. São Paulo: RT, 2015. 


\section{Informações adicionais e declarações dos autores (integridade científica)}

Declaração de conflito de interesses (conflict of interest declaration): Os autores atuam como advogados em processo, em grau recursal, a partir do qual surgiu a temática que veio a ser aprofundada e tratada no artigo. Contudo, embora parte da problemática ora analisada seja abordada no recurso, a tese tanto ultrapassa os limites estritos do feito quanto está dissociada dos interesses da causa. Importante ressaltar, ainda, que o feito em questão se encontra em fase recursal, já tendo sido apresentadas as principais peças processuais (na fase) - razões e contrarrazões -, o que elimina qualquer possibilidade de "inovação" quanto aos argumentos já lançados nos autos. De todo modo, o patrocínio da referida causa não impacta a neutralidade científica que orientou a pesquisa e as conclusões apresentadas.

Declaração de autoria e especificação das contribuições (declaration of authorship): todas e somente as pessoas que atendem os requisitos de autoria deste artigo estão listadas como autores; todos os coautores se responsabilizam integralmente por este trabalho em sua totalidade.

- Ivan Navarro Zonta: projeto e esboço inicial (conceptualization), desenvolvimento da metodologia (methodology), coleta e análise de dados (data curation), levantamento bibliográfico (investigation), revisão bibliográfica (investigation), redação (writing - original draft), implementação inicial das modificações apontadas no processo editorial, aprovação da versão final (writing - final draft).

- Guilherme Brenner Lucchesi: revisão bibliográfica (investigation), participação ativa nas discussões dos resultados (validation), revisão crítica com contribuições substanciais (writing - review and editing), revisão das modificações apontadas no processo editorial, aprovação da versão final (writing - final draft).

Declaração de ineditismo e originalidade (declaration of originality): os autores asseguram que o texto aqui publicado não foi divulgado anteriormente em outro meio e que futura republicação somente se realizará com a indicação expressa da referência desta publicação original; também atestam que não há plágio de terceiros ou autoplágio. 


\section{Dados do processo editorial}

(http://www.ibraspp.com.br/revista/index.php/RBDPP/about/editorialPolicies)

- Recebido em: 29/03/2020

Equipe editorial envolvida

- Controle preliminar e verificação de plágio:

- Editor-chefe: 1 (VGV) 30/03/2020

- Avaliação 1: 03/04/2020

- Editor-associado: 1 (JJEC)

- Avaliação 2: 07/04/2020

- Revisores: 3

- Avaliação 3: 13/04/2020

- Decisão editorial preliminar: 05/05/2020

- Retorno rodada de correções: 19/05/2020

- Decisão editorial final: 21/05/2020

\section{COMO CITAR ESTE ARTIGO:}

LUCCHESI, Guilherme Brenner; ZONTA, Ivan Navarro. Sequestro dos proventos do crime: limites à solidariedade na decretação de medidas assecuratórias.

Revista Brasileira de Direito Processual Penal, Porto Alegre, vol. 6, n. 2, p. 735-764, maio/ago. 2020. https://doi.org/10.22197/rbdpp.v6i2.353

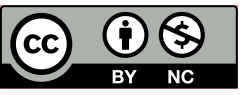

Esta obra está licenciada com uma Licença Creative Commons Atribuição-NãoComercial 4.0 Internacional. 